tron-diffraction observations on powdered ferrous oxide at $80^{\circ} \mathrm{K}$. that the magnetic moments of the $\mathrm{Fe}^{2+}$ ions are parallel within a given (111) sheet of $\mathrm{Fe}^{2+}$ ions and antiparallel between adjacent sheets. This picture is consistent with the X-ray observations, which indicate the development of a unique triad axis normal to a set of (111) planes.

The reason for the marked difference in the magnitude of the crystal structure change at low temperatures of ferrous oxide samples of different iron content (see Table 2) is not clear. It is unlikely that the difference is due to a variation of the transition temperature $T_{\lambda}$ between the different samples. Such an explanation would require a change of $T_{\lambda}$ of approximately $100^{\circ} \mathrm{K}$. when the iron content of the sample increases from 47.5 to 48.5 atomic $\%$, whereas the actual change in $T_{\lambda}$ for this range is probably much less. Thus Bizette (1946) found that $T_{\lambda}$ was $198^{\circ} \mathrm{K}$. for a sample of maximum iron content, and Millar (1929) that $T_{\lambda}$ was $185^{\circ} \mathrm{K}$. for a sample which was probably of minimum iron content. Further, Bizette measured the variation of $T_{\lambda}$ as a function of composition in the solid solution system $\mathrm{FeO}-\mathrm{MgO}$, and found that on lowering the atomic concentration of iron by $1 \%$ (by replacement of $\mathrm{Fe}^{2+}$ with the nonmagnetic ion $\mathrm{Mg}^{2+}$ ) a reduction in $T_{\lambda}$ of $5^{\circ} \mathrm{K}$. only took place.

It appears reasonable to expect the magnitude of the deformation below $T_{\lambda}$, which takes place in a direction normal to (111) ionic sheets, to increase as the number of vacant sites and $\mathrm{Fe}^{3+}$ ions within the sheets is reduced, i.e. as the stoichiometric composition is approached. However, on Bénard's interpretation of the room-temperature structure, the deformation is extremely small for stoichiometric $\mathrm{FeO}$ and increases rapidly as the proportion of dissolved $\mathrm{Fe}^{2+}$ ions increases. We believe that this is therefore additional evidence in favour of the interpretation of Jette \& Foote.

\section{References}

Bénard, J. (1937). C. R. Acad. Sci., Paris, 205, 912.

Bénard, J. (1939). Ann. Chim. (11), 12, 5.

Bénard, J. \& Chaudron, G. (1936). C. R. Acad. Sci., Paris, 202, 1336.

Bizette, H. (1946). Ann. Phys., Paris, (12), 1, 295.

Ellefson, B. S. \& TAYLoR, N.W. (1934). J. Chem. Phys. 2, 58.

Jette, E. R. \& Foote, F. (1933a). J. Chem. Phys. 1, 29. Jette, E. R. \& Foote, F. (1933b). Trans. Amer. Inst. Min. (Metall.) Engrs. 105, 276.

Millar, R. W. (1929). J.Amer. Chem. Soc. 51, 215.

Rooksby, H. P. (1948). Acta Cryst. 1, 226.

Shuld, C. G., Strauser, W. A. \& Wollan, E. O. (1951). Phys. Rev. 83, 333.

SmaRT, J. S. \& GREenwald, S. (1950). Nature, Lond. 166, 523.

Tomвs, N. C. \& RooksBy, H. P. (1950). Nature, Lond. $165,442$.

Wyckoff, R. W. G. (1952). Crystal Structures, vol. 1. New York: Interscience Publishers.

Acta Cryst. (1953). 6, 831

\title{
The Structure of Dimethyl Oxalate
}

\author{
By Maryon W. Dougrll and G. A. Jeffrey* \\ Department of Inorganic and Physical Chemistry, The University of Leeds, England
}

(Received 7 April 1953)

\begin{abstract}
An X-ray analysis of the crystal structure of dimethyl oxalate shows that the molecule has a planar trans-trans configuration, which is the planar structure of least steric interference. The bond lengths and valency angles are $\mathrm{C}^{1}-\mathrm{C}^{1} 1 \cdot 53 \pm 0 \cdot 08, \mathrm{C}^{2}-\mathrm{O}^{1} 1 \cdot 19, \mathrm{C}^{1}-\mathrm{O}^{2} 1 \cdot 31, \mathrm{O}^{2}-\mathrm{C}^{2} 1 \cdot 46 \pm 0.05 \AA, \mathrm{C}^{1}{ }_{-} \mathrm{C}^{1}-\mathrm{O}^{1}$ $125^{\circ}, \mathrm{C}^{1}-\mathrm{C}^{1}-\mathrm{O}^{2} 110^{\circ}, \mathrm{O}^{1}-\mathrm{C}^{1}-\mathrm{O}^{2} 125^{\circ}, \mathrm{C}^{1}-\mathrm{O}^{2}-\mathrm{C}^{2} 118^{\circ} \pm 3^{\circ}$. The intramolecular methyl to carbonyl distance is $2.70 \AA$. Of the four intermolecular distances which are less than $3.95 \AA$, three at 3.35 , 3.54 and $3.57 \AA$ correspond to co-ordination of carbonyl oxygen atoms around a methyl group very approximately in the directions of the $\mathrm{C}-\mathrm{H}$ bonds. It is suggested that there is weak association or polarization bonding between the carbonyl and the methyl groups which accounts for the anomalous melting point. This may also provide an explanation of the differences which have been reported in the Raman spectra of the solid and liquid.
\end{abstract}

\section{Introduction}

In the recent crystal-structure analyses of $\alpha$-anhydrous oxalic acid (Cox, Dougill \& Jeffrey, 1952),

\footnotetext{
* Now at Chemistry Department, University of Pittsburgh, U.S.A.
}

oxalic acid dihydrate (Ahmed \& Cruickshank, 1953), ammonium oxalate hydrate (Jeffrey \& Parry, 1952) and sodium oxalate (Jeffrey \& Parry, 1953) it was found that the configuration of the $(\mathrm{COO})_{2}$ is planar in the acids but not necessarily so in the salts. In $\left(\mathrm{NH}_{4}\right)_{2}(\mathrm{COO})_{2} \cdot \mathrm{H}_{2} \mathrm{O}$ the oxalate ion is non-planar with 
the carbonyl groups inclined to each other at $28^{\circ}$; in $\mathrm{Na}_{2}(\mathrm{COO})_{2}$ the ion is exactly planar. In each of the structure determinations of acids and salts the length of the central C-C bond was found to be $1.54 \AA$ within the limits of the experimental errors, which ranged from standard deviations of $0.010 \AA$ in $\alpha(\mathrm{COOH})_{2}$ to about $0.02 \AA$ in the less accurate analyses of the salts.

It appears that intermolecular as well as intramolecular forces may determine the stereochemistry of the oxalate group, and it is of interest, therefore, to examine the structure in an environment devoid of strong hydrogen bonds and ionic forces. The dimethyl ester of oxalic acid was selected for study since it is a low-melting-point crystalline solid with physical properties consistent with weak intermolecular cohesion.

\section{Experimental}

The dimethyl oxalate was recrystallized from dry methyl alcoliol. The crystals were soft, volatile, monoclinic prisms, m.p. $54^{\circ}$ C., tabular on (010) with the forms $\{110\}$ and $\{011\}$ or $\{120\}$. The optical data given by Winchell (1943) is $N_{g}=1.58, N_{m}=1.55$, $N_{p}=1 \cdot 43,2 \mathrm{~V}=70^{\circ}$. The crystals are too soft to cleave cleanly and deform on pressure into layers normal to the $b$ axis. Crystals with approximately uniform cross-section of $0.05 \mathrm{~cm}$. were selected for the X-ray measurements, and to prevent evaporation they were enclosed in thin-walled Lindemann glass tubes. The unit-cell dimensions, measured from rotation photographs about the principal axes, were

$$
\begin{gathered}
a=3 \cdot 90, b=11 \cdot 88, c=6 \cdot 21 \AA, \quad(\text { all } \pm 0 \cdot 04 \AA), \\
\beta=103 \cdot \mathrm{I}_{ \pm 0} 0 \cdot 5^{\circ} .
\end{gathered}
$$

The space group, uniquely determined by the systematic extinctions, is $P 2_{1} / n$, (not $P 2_{1} / m$ as reported by Wood (1926)). There are two molecules in the unit cell and the calculated density of 1.39 g.cm..$^{-3}$ is in agreement with an observed value of $1.4 \mathrm{~g} . \mathrm{cm} .^{-3}$, which was difficult to measure by flotation because of hydrolysis in aqueous solutions and high solubility in most organic liquids. The molecular symmetry is centric and, with the assumption that the trigonal carbon valencies are planar, the oxalate group $(\mathrm{COO})_{2}$ is planar, as in the acids and the sodium salt.

The experimental data for the structure analysis are the intensities of the reflexions in the three principal zones. Of 176 reflexions within the range of $\mathrm{Cu} K \alpha$ radiation, 136 were observed: $68(0 \mathrm{kl})$ 's, $22(h 0 l)$ 's and $46(h k 0)$ 's. There was a marked fall-off in the intensities with increase of $\sin \theta$ due to the relatively large thermal motion at room temperature, and many of the unobserved reflexions were at high angles: The intensities were estimated by eve, with the aid of calibration charts, from Weissenberg photographs of the zero layers of the principal axes. No correction was made for crystal absorption and the experimental errors from this omission were estimated as about $3 \%$ of the structure amplitudes. The Cochran chart was used for obtaining the Lorentz and polarization factors. The scale $(s)$ and thermal factors $(B)$ were obtained from the plot of

$$
\log F_{c} / F_{o}=\log s+(B / 2 \cdot 303)\left(\sin ^{2} \theta / \lambda^{2}\right) .
$$

These were calculated for each projection, in the first instance after a tria $\iota$ structure and later during the parameter refinement for more precise values.

\section{The structure determination}

The approximate structure was determined by trialand-error methods with some guidance in one projection from the inequality method of direct sign determination (Harker \& Kasper, 1948). The atomic parameters were refined by two-dimensional Fourier syntheses and difference syntheses.

The short $a$ axis of the unit cell showed that the $(\mathrm{COO})_{2}$ plane of the molecule cannot be inclined at more than $40^{\circ}$ to $(100)$ and that in projection on that plane all atoms might be resolved. The $a$-axis length also limited the possible inclination of the $\mathrm{O}-\mathrm{CH}_{3}$ bond to the oxalate plane. Of the various models considered only the planar trans-trans configuration, $\mathrm{I}$, was compatible with the $\mathrm{X}$-ray intensities; (we have adopted this nomenclature since the $\mathrm{C}=\mathrm{O}$ bonds are trans with reference to the central $\mathrm{C}-\mathrm{C}$ bond, and for the configuration about $\mathrm{C}^{1}-\mathrm{O}^{2}$ we follow the convention used by Marsden \& Sutton (1936) in describing methyl acetate).

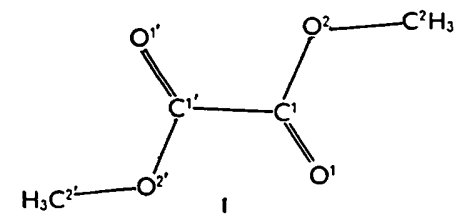

The orientation of the molecule relative to the $b$ and $c$ axes was found by trial. The approximate $y, z$ parameters were refined by two-dimensional Fourier projections (Fig. 1), followed by difference, $\left(F_{o}-F_{c}\right)$ synthesis (Fig. 2) to reduce termination-of-series errors. In the projection (Fig. 1) the electron densities of the oxygen atoms appear to be disproportionally large relative to those of the carbon atoms, and by assuming gaussian peaks the ratio of the number of electrons was estimated at $\mathrm{C}^{1}: \mathrm{C}^{2}: 0^{1}: 0^{2}$ as $4 \cdot 3: 3 \cdot 6: 7 \cdot 8: 6 \cdot 5$. This effect is due mainly to termination-of-series errors, since the difference map (Fig. 2) shows no significant negative or positive values at the carbon and oxygen positions with $F_{c}$ from normal $\mathrm{C}$ and $\mathrm{O}$ atomic scattering factors. The most significant feature of this difference map is the positive region associated with the methyl carbon atom; this corresponds to the electron distribution of the hydrogen atoms which were omitted in calculating the structure factors. When the contribution from these was included, 


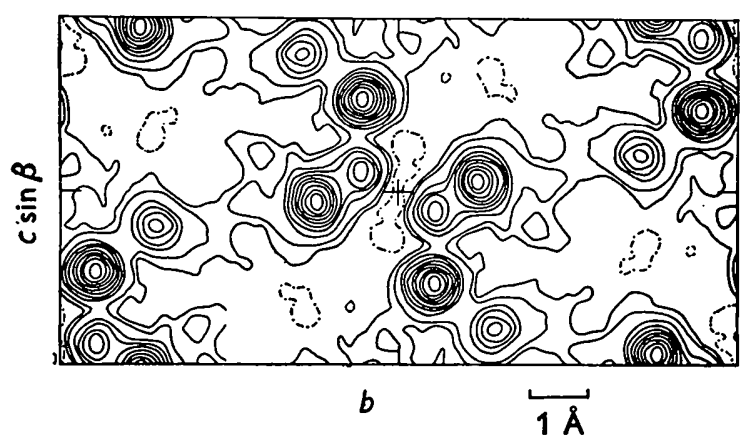

Fig. 1.

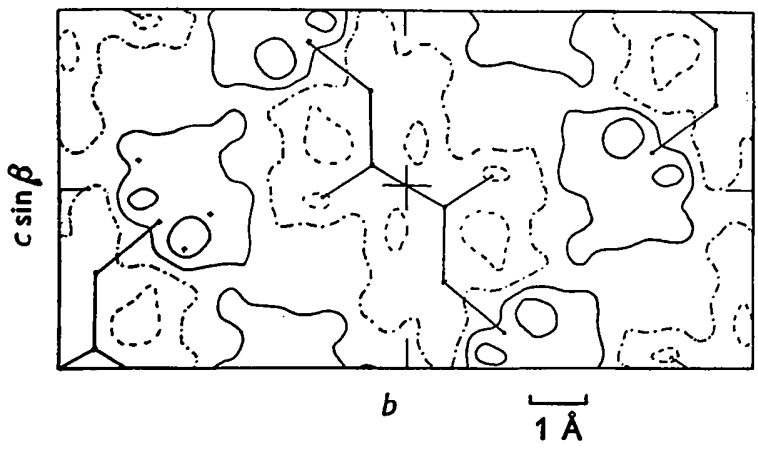

Fig. 2.

Fig. 1. Electron density projected along $a$. Contour interval: 1.0 e. $\AA^{-2}$. Chain line: 0.0 e. $\AA^{-2}$.

Fig. 2. $\left(F_{o}-F_{c}\right)$ projected along $a$. Contour interval: 0.5 e. $\AA^{-2}$. Full lines: positive; chain line: zero; broken lines: negative.

Table 1. The atomic co-ordinates

\begin{tabular}{cccc} 
& \multicolumn{3}{c}{ Fractions of monoclinic axes } \\
& $x$ & $y$ & $z$ \\
$\mathrm{C}^{1}$ & 0.095 & 0.052 & 0.056 \\
$\mathrm{C}^{2}$ & 0.272 & 0.143 & 0.405 \\
$\mathrm{O}^{1}$ & 0.244 & 0.119 & -0.031 \\
$\mathrm{O}^{2}$ & 0.095 & 0.051 & 0.267
\end{tabular}

assuming a non-rotating methyl group oriented with the $\mathrm{C}-\mathrm{H}$ bonds directed approximately toward the coordinating carboxyls of adjacent molecules (see below), there was a significant improvement in the agreement index from $R=0.16$ to $0.12\left(R=\Sigma\left|F_{o}-F_{c}\right| \div \Sigma\left|F_{o}\right|\right)$.

In the $(h k 0)$ zone, four reflexions had intensities corresponding to unitary structure factors greater than $0 \cdot 4$, and use of the inequality relationships established the phases for five reflexions. Since the $x$ co-ordinates of the atoms were known from the $a$ projection, the planar model could be uniquely oriented in the unit cell to conform to the amplitudes and phases of these five planes. In projection down the $c$ axis the atoms overlapped in pairs, with no resolution of the peaks for $\mathrm{O}^{1}, \mathrm{C}^{2}$ and $\mathrm{O}^{2}, \mathrm{C}^{1}$ of the same half molecule.

In the $b$-axis projection (Fig. 3), for which only 23(h0l) structure factors were available, the oxygen atoms were resolved and the carbon atoms from



Fig. 3. Electron density projected along $b$. Contour interval: 1.0 e. $\AA^{-2}$. Broken line: 1.0 e. $\AA^{-2}$.

A C 6
In Angström units, referred to orthogonal ( $X^{\prime}$ is normal to the $b$ and $c$ axes)

\begin{tabular}{ccr}
$X^{\prime}$ & $Y$ & \multicolumn{1}{c}{$Z$} \\
$0 \cdot 361$ & $0 \cdot 618$ & $0 \cdot 264$ \\
1.034 & 1.699 & $2 \cdot 275$ \\
0.927 & 1.414 & -0.409 \\
0.361 & 0.606 & $1 \cdot 574$
\end{tabular}

adjacent molecules were superimposed. The common $z$ co-ordinates for $\mathrm{O}^{1}$ and $\mathrm{O}^{2}$ from the $a$ - and $b$-axis projections agreed within $0.025 \AA$, and it was assumed that the $x$ and $y$ co-ordinates were equally reliable. The oxygen atoms were therefore removed from the $c$-axis projection by computing the synthesis with $\left(F_{o}-F_{c}\right.$ (oxygens)) as coefficients (Fig. 4). This gave



Fig. 4. $\left(F_{o}-F_{O}\right)$ electron density projected along $c$. Contour interval: 1 e. $\AA^{-2}$. Chain line: 0.0 e. $\AA^{-2}$. Crosses: oxygen positions.

a clear indication of the planar configuration of the whole molecule and its inclination to the $a$ axis. The $x$ co-ordinates of the carbon atoms were derived from this synthesis.

The atomic co-ordinates are given in Table 1. The intramolecular dimensions and the principal intermolecular separations of atoms are given in Table 2 .

The structure factors were calculated from James \& Brindley scattering factors for $\mathrm{C}$ and $\mathrm{O}$ with a mean thermal factor of $B=2 \cdot 95 \AA^{-2}$. The agreement indices for the $(0 k l),(h 0 l),(h k 0)$ zones were $0 \cdot 16,0 \cdot 19,0 \cdot 17$, respectively, excluding the hydrogen electron contributions. The observed and calculated structure factors are given in Table 4. 
Tàble 2. Interatomic distances and angles

Intramolecular

$\begin{array}{llll}\mathrm{C}^{1}-\mathrm{C}^{1} & 1 \cdot 53 \AA & \mathrm{C}^{1}-\mathrm{C}^{1}-\mathrm{O}^{1} & 125^{\circ} 2^{\prime} \\ \mathrm{C}^{1}-\mathrm{O}^{1} & 1 \cdot 19 & \mathrm{C}^{1}-\mathrm{C}^{1}-\mathrm{O}^{2} & 109^{\circ} 48^{\prime} \\ \mathrm{C}^{1}-\mathrm{O}^{2} & 1 \cdot 31 & \mathrm{O}^{1}-\mathrm{C}^{1}-\mathrm{O}^{2} & 124^{\circ} 55^{\prime} \\ \mathrm{C}^{2}-\mathrm{O}^{2} & 1 \cdot 46 & \mathrm{C}^{1}-\mathrm{O}^{2}-\mathrm{C}^{2} & 118^{\circ} 11^{\prime} \\ & & & \\ \mathrm{C}^{2}-\mathrm{O}^{1} & 2 \cdot 70 \AA & \mathrm{C}^{2}-\mathrm{C}^{1} & 2 \cdot 38 \AA \\ \mathrm{O}^{1}-\mathrm{O}^{2} & 2 \cdot 21 & \mathrm{O}^{1}-\mathrm{O}^{1} & 3.48 \\ \mathrm{O}^{1}-\mathrm{O}^{2} & 2 \cdot 66 & \mathrm{O}^{2}-\mathrm{O}^{2 \prime} & 3 \cdot 45\end{array}$

Intermolecular

$\begin{array}{lllll}\mathrm{C}^{2}-\mathrm{O}^{1} & 3 \cdot 35 \AA & \text { I-II } & \text { I } & x, y, z . \\ \mathrm{C}^{2}-\mathrm{O}^{1} & 3 \cdot 54 & \text { I-III } & \text { II } & \frac{1}{2}+x, \frac{1}{2}-y, \frac{1}{2}+z . \\ \mathrm{C}^{2}-\mathrm{O}^{1} & 3 \cdot 57 & \text { I-IV } & \text { III } & x, y, 1+z, 1-z . \\ \mathrm{O}^{2}-\mathrm{O}^{2}, & 3 \cdot 37 & \text { I-III' } & \text { III' } & -x,-y, 1-z, \frac{1}{2}, \frac{1}{2}-y, \frac{1}{2}+z \\ \mathrm{O}^{2}-\mathrm{O}^{2}, & 3 \cdot 96 & \text { I-V } & \text { IV } & x-\frac{1}{2} \\ \mathrm{O}^{2}-\mathrm{O}^{\prime} & 4 \cdot 34 & \text { I-III } & \text { V } & 1-x,-y, 1-z .\end{array}$

The standard deviations of the atomic co-ordinates from the resolved $a$-axis projection, calculated by the method of Cruickshank (1949) are $\mathrm{C}^{1} 0.016, \mathrm{C}^{2} 0.012$, $0^{1} 0.011, \mathrm{O}^{2} 0.010 \AA$. The standard deviation of the central $\mathrm{C}-\mathrm{C}$ bond is estimated as about $0.03 \AA$, which corresponds to a probable limit of error of $\pm 0.08 \AA$. The comparative inaccuracy of this measurement is due to a combination of the low value for the curvature of the $\mathrm{C}^{1}$ peak and the centrosymmetrical relationship of the two carbon atoms. The probable limit of error for the other bond lengths is about $\pm 0.05 \AA$. Within similar limits the molecule is planar; the equation of the plane through the oxygen atoms and the origin is

$$
2 \cdot 47 x-1 \cdot 61 y+0 \cdot 05 z=0
$$

and $\mathrm{C}^{1}$ and $\mathrm{C}^{2}$ are -0.029 and $-0.019 \AA$ respectively out of this plane.

\section{The molecular structure}

The planar trans-trans structure of the molecule of dimethyl oxalate conforms to the stereochemistry of the oxalic acids as regards orientation about the central $\mathrm{C}-\mathrm{C}$ bond, and to that of the simple carboxylic esters in the configuration of the carbomethoxy group. As with the acids, the coplanarity of the carboxyl groups, which might be regarded as characteristic of conjugation and $\pi$-bonding across the $\mathrm{C}-\mathrm{C}$ bond, is not associated with a shortening in length relative to $1.54 \AA$, although in this analysis the measurement of that bond length is particularly insensitive and the observation is much less critical than for the $\alpha$-oxalic acid and, to a lesser degree, the other analyses of the acid and its salts. The configuration of the carbomethoxy group has been previously studied in other molecules in the liquid and vapour states by dipolemoment and electron-diffraction methods. From the value of the moment of methyl acetate vapour $(1 \cdot 67 \mathrm{D})$ and solution in benzene $(1 \cdot 78 \mathrm{D})$ it was concluded that in both phases the molecules are very close to the planar trans configuration, II, (Eucken
\& Meyer, 1929; Marsden \& Sutton, 1936). Zahn's (1932) dipole-moment results also indicated that there was no appreciable free rotation about the $\mathrm{C}-\mathrm{O}$ bond at temperatures up to $243^{\circ} \mathrm{C}$.
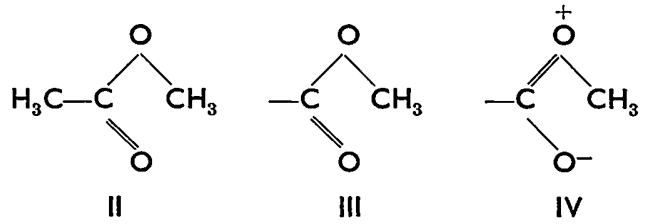

The electron-diffraction study of methyl formate and methyl acetate by O'Gorman, Shand \& Schomaker (1950) largely confirms these observations, with an estimate of $25^{\circ}$ for the average dihedral angle of rotation from the planar configuration under the conditions of their experiment. They give the following values for the dimensions of the methyl acetate molecule: $\mathrm{C}-\mathrm{C} 1 \cdot 52 \pm 0 \cdot 04, \mathrm{C}=\mathrm{O} 1 \cdot 22 \pm 0 \cdot 03, \mathrm{C}-0 \mathrm{l} \cdot 36 \pm 0 \cdot 04$, $\mathrm{O}-\mathrm{CH}_{3} \quad 1 \cdot 46 \pm 0.04 \AA, \mathrm{C}-\mathrm{C}-\mathrm{O} \quad 116 \pm 3, \mathrm{C}-\mathrm{O}-\mathrm{C} \quad 113 \pm 3$, $\mathrm{O}-\mathrm{C}=\mathrm{O} 124 \pm 4^{\circ}$. The restricted rotation of the methyl carbon atom about the $\mathrm{C}-\mathrm{O}$ bond is the consequence of the $\pi$-character of the bonding due to the resonance structures III and IV. This is also manifested in the C-O bond length, which is significantly shorter than that of the $\mathrm{O}-\mathrm{CH}_{3}$. The same general features are found in the dimethyl oxalate structure; the $\mathrm{O}-\mathrm{CH}_{3}$ bond length is in exact agreement with that from the methyl acetate; the $\mathrm{C}-\mathrm{O}$ bond is $0.05 \AA$ shorter but the difference lies within the combined experimental errors. The dimensions of the carboxyl system do not differ significantly from those found in $\alpha$-oxalic acid, $\mathrm{V}$, by Cox et al. (1952).

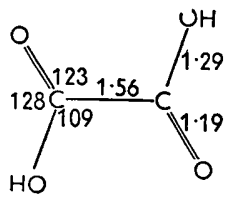

V

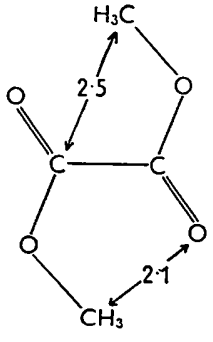

VI
The $\mathrm{C}-\mathrm{O}-\mathrm{CH}_{3}$ angle is significantly greater than tetrahedral, as might be expected from the bond character implied in the resonance formula IV and the non-bonding interaction between the methyl group and the carboxyl oxygen at $2 \cdot 70 \AA$. In diethyl terephthalate (Bailey, 1949), the whole molecule, with the exception of the terminal $\mathrm{CH}_{3}$ of the ethyl group, is also planar and, within the limits of the experimental errors, the relevant bond lengths and valency angles are in agreement with these results.

On the basis of the dimensions of the trans-trans molecule, it is apparent that the planar trans-cis isomer, VI, has an energetically unfavourable configuration because of the methyl carbon $\mathrm{C}^{2}$ approach to the carbonyl oxygen $\mathrm{O}^{1^{\prime}}$ at $2 \cdot 1 \AA$ and the carbon 
$\mathrm{C}^{1 \prime}$ at $2.5 \AA$. A rotation about the central $\mathrm{C}-\mathrm{C}$ bond would relieve the $\mathrm{CH}_{3} \cdots \mathrm{O}^{\prime \prime}$ repulsion energy but leave unchanged that of the $\mathrm{CH}_{3} \cdots \mathrm{C}^{\mathbf{1}^{\prime}}$. A planar cis-cis isomer is impossible owing to the near superposition of the two methyl groups, and in fact only one form of dimethyl oxalate is known.

\section{The intermolecular structure}

In keeping with the low melting point, high vapour pressure and soft character of the crystals, the structure is of the molecular type with no short interatomic distances corresponding to strong linkages between molecules. The molecular packing takes a form, common to the crystal structures of planar molecules, in which the molecules lie in two planes alternately inclined approximately at right angles to each other (Figs. 5 and 6), (cf. naphthalene and anthracene (Abrahams, Robertson \& White, 1949; Mathieson, Robertson \& Sinclair, 1950)).

The crystals deform under slight pressure in layers normal to the $b$ axis. The reason for this is apparent from the molecular packing: in directions other than normal to the $b$ axis the molecules are staggered in position and it is only parallel to $(010)$ that planes
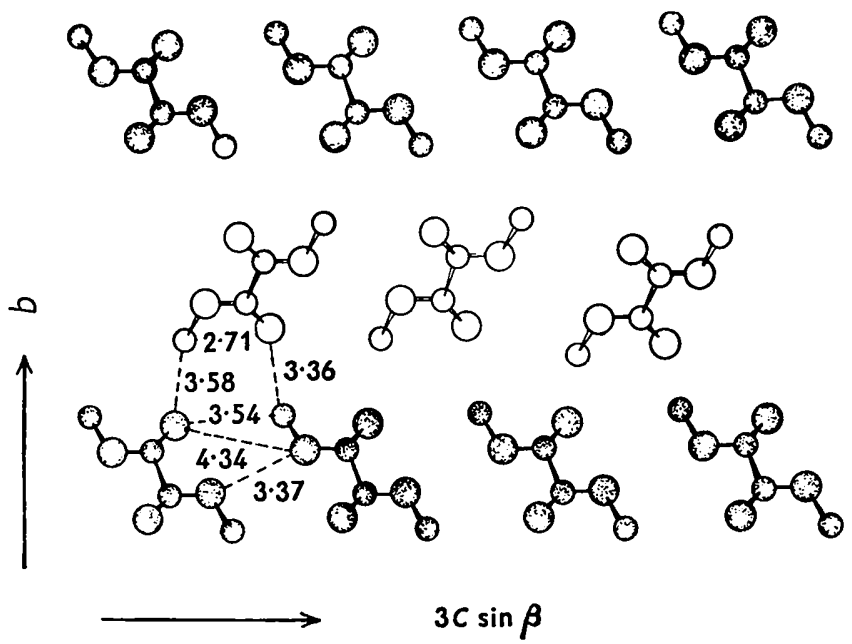

Fig. 5. Structure of dimethyl oxalate projected along $a$.
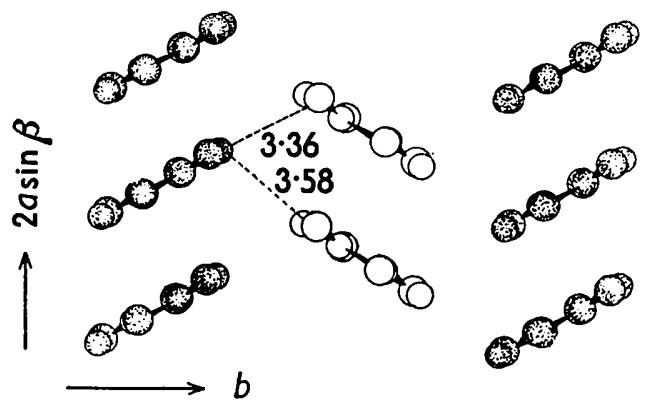

Fig. 6. Structure of dimethyl oxalate projected along $c$.

which do not intersect the molecules can be drawn through the crystal structure.
The shorter of the intermolecular distances are given in Table 2. It is a notable feature of these that, of the four closest, three correspond to co-ordination of carbonyl oxygen atoms around the methyl group at $3.35,3.54$, and $3.57 \AA$. The fourth distance is $3.4 \AA$ between ester oxygen atoms, and all other neighbours are separated by $4 \cdot 0,4 \cdot 3 \AA$ and greater distances. The arrangement of the three carbonyl groups, which are from different molecules, around the methyl group is illustrated in Fig. 7. On the right hand side, the $\mathrm{C}-\mathrm{O}$

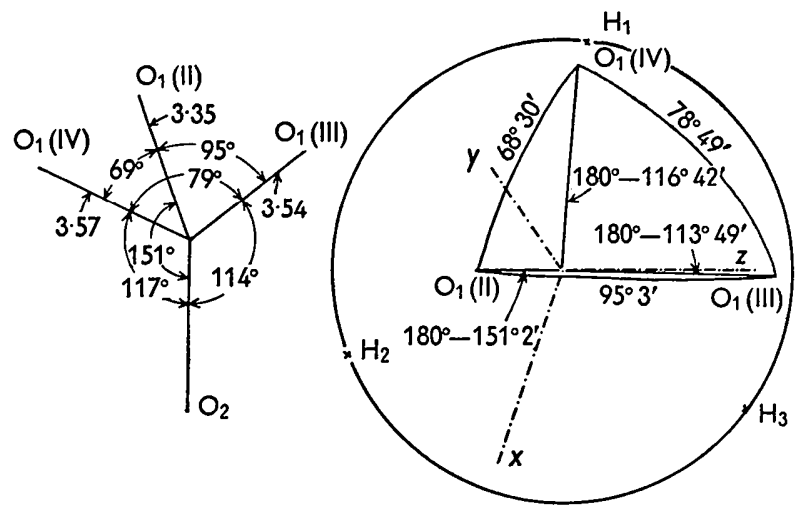

Fig. 7. (a) Distribution of carbonyl oxygen atoms of adjacent molecules around a methyl group relative to the direction of the $\mathrm{O}^{2} \mathrm{C}^{2}$ bond. (b) Stereographic projection with $\mathrm{O}^{2} \mathrm{C}^{2}$ as pole axis.

directions and those of the $\mathrm{C}-\mathrm{H}$ bonds, assuming tetrahedral angles, are compared on a stereographic projection with $\mathrm{O}^{2} \mathrm{C}^{2}$ as the pole axis. Owing to the proximity of the carbonyl oxygen atom in the same molecule, which is only $2.7 \AA$ away, the $\mathrm{O}^{2} \mathrm{C}^{2} \mathrm{H}$ angles will probably be somewhat distorted from tetrahedral. The greatest distortion is likely to be that which opens the $\mathrm{O}^{2} \mathrm{C}^{2} \mathrm{H}$ angle in the plane of the molecule so as to bring the hydrogen locus in Fig. 7 closer to the pole of the stereographic projection in the vicinity of the point $\mathrm{O}(\mathrm{II})$.

There is no direct evidence of the exact location of the hydrogen atoms from this analysis, and the methyl group may be rotating freely or may be partially restricted by the electrostatic field of the polar oxygen atoms. In calculating the X-ray scattering of the hydrogen atoms (see above), a non-rotating group was assumed and the atoms were assigned the positions marked in Figs. 2 and 7. Although this resulted in a

Table 3. Melting and boiling points of some carboxylic esters

$\begin{array}{lcc} & \text { M.p. }\left({ }^{\circ} \mathrm{C} .\right) & \text { B.p. }\left({ }^{\circ} \mathrm{C} .\right) \\ \text { Dimethyl oxalate } & +54 & 163 \\ \text { Methyl ethyl oxalate } & \text { Liq. } & 174 \\ \text { Diethyl oxalate } & -41 & 185 \\ \text { n-Dipropyl oxalate } & -44.3 & 214 \\ \text { Dimethyl malonate } & -62 & 181 \\ \text { Diethyl malonate } & -50 & 199 \\ \text { Dimethyl succinate } & +19.5 & 193 \\ \text { Diethyl succinate } & -21 & 218\end{array}$


Table 4. Observed and calculated structure factors

( $F_{c}^{\prime}$ including hydrogen atoms)

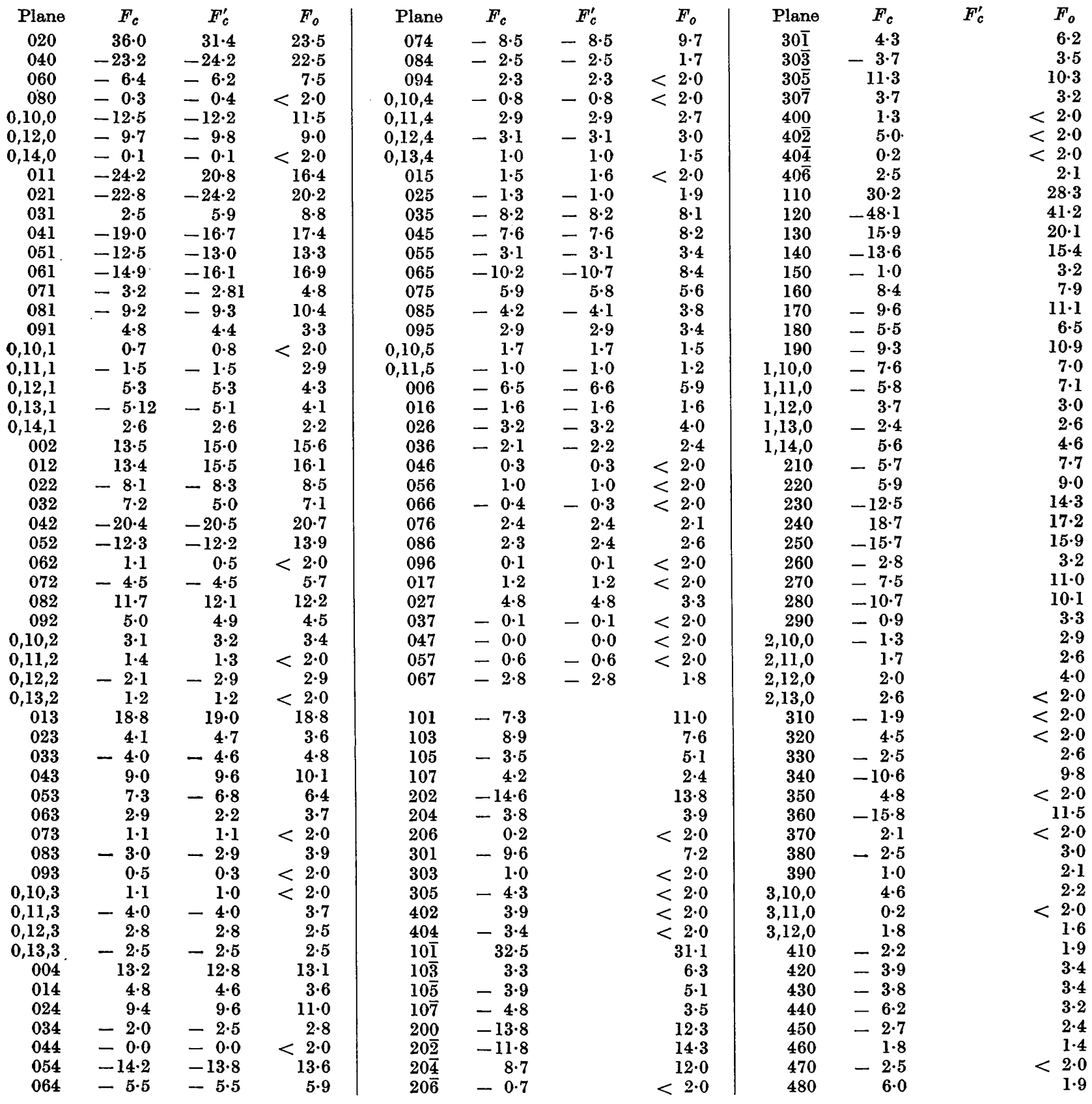

significant improvement in the structure-factor agreement, the accuracy of the present experimental data is"inadequate to distinguish between this or any other fixed orientation and hindered or free rotation.

The intermolecular $\mathrm{C} \cdots \mathrm{O}^{1}$ directions all lie within the tetrahedral $\mathrm{H}-\mathrm{C}-\mathrm{H}$ angles of the methyl group. This suggests that there is association between the carbonyl oxygens and the methyl group as a whole, rather than along particular $\mathrm{C}-\mathrm{H}-\mathrm{O}$ directions. Except for the co-ordination, the distances of about $3.5 \AA$ would not be regarded as particularly characteristic of $\mathrm{C}-\mathrm{H}-\mathrm{O}$ hydrogen bonds, which, if they exist, are in general too weak to be apparent from the results of crystal-structure studies. They could, however, correspond to the type of association often classified as hydrogen bonding, which is manifested in observations of anomalous solubilities and of infra-red displacements of certain compounds in donor solvents (cf. Hunter, 1946). The attraction between molecules which gives rise to complex-formation between nitro 
compounds, quinones etc. and aromatic hydrocarbons, amines, phenols has been described as 'polarization 'bonding' by McKeown, Ubbelohde \& Woodward (1951). In particular, this term was applied to the unusually close approach of $2.66 \AA$ between nitro oxygen and aromatic carbon atom in $p$-nitroanaline; but this was considered to be an extreme case, for in the crystal structures of those molecular complexes which have been studied no short intermolecular distances are found. In dimethyl oxalate the association is similarly between a strongly polar group, $\delta+\delta-$

$\mathrm{C}=\mathrm{O}$, and a polarizable one, $-\mathrm{CH}_{3}$, which are not separated by particularly short intermolecular distances. In the absence of more detailed understanding of these forces, polarization bonding would appear to be a more appropriate description than $\mathrm{C}-\mathrm{H} \cdots \mathrm{O}$ hydrogen bonding.

Dimethyl oxalate shows a marked first-member anomaly in melting point compared with the melting points of other alkyl oxalates and carboxylic esters (Table 3). In contrast, the boiling points of the oxalate esters are in normal sequence and the vapour-pressure data reported by Shull (1947) for the dimethyl and diethyl esters give similar Trouton constants (c. 30). The high melting point of the dimethyl ester would appear therefore to be a consequence of the methylto-carbonyl association in combination with the possibility of appropriately compact arrangement of molecules in the crystal. It is therefore a crystalline solid at room temperature for much the same reasons that molecular compound formation takes place between molecules containing polarizing and polarizable atoms (cf. Wallwork \& Harding, 1953). A similar effect is found to a lesser degree in dimethyl succinate, which could have a similar crystal structure, but is absent in the malonate series where the non-centric molecular configuration would compel a different type of molecular packing (cf. the crystal structures of the odd and even series of dicarboxylic acids). That the $\mathrm{CH}_{3} \cdots \mathrm{O}$ association is significant only in the methyl and not in the ethyl derivative is in keeping with evidence that the $\mathrm{CH} \cdots \mathrm{O}$ is a weak interaction which becomes apparent only in suitable polar environment (Hunter, 1946); it is provided in this structure within the molecule by the adjacent ester oxygen which renders the $\mathrm{CH}_{3}$ more polarizable to the external influence of the carbonyl dipoles.

From the examination of the Raman spectra of dimethyl oxalate, Saksena (1940) reported marked changes in frequency and intensity in passing from solid to liquid. This observation was interpreted as due to a reduction in the $\mathrm{C}=\mathrm{O}$ force arising from a transition at the melting point from the trans-trans molecule, I, to the trans-cis isomer, VI. In view of the steric interference in a trans-cis isomer (see above), this is a most unlikely explanation. It is more reasonable to ascribe the spectral differences to changes in the force constant of the $\mathrm{C}=\mathrm{O}$ bond with the disruption of the methyl-to-carbonyl association by thermal motion at the melting point. Infra-red spectrograms of dimethyl oxalate solutions in $\mathrm{CS}_{2}$ and $\mathrm{CCl}_{4}$ at different concentrations showed no change in the $\mathrm{C}-\mathrm{H}$ frequencies at 2900 and $3000 \mathrm{~cm}^{-1}$; and this also supports the view that the association is weak and only significant in the solid state.

The authors wish to thank Prof. E. G. Cox for his interest and criticism, Dr P. Wheatley for discussion of the Raman and infra-red data and Dr D. E. C. Corbridge of Messrs Albright and Wilson Ltd for providing the infra-red spectrogram. One of us (M.W.D.) is grateful to the Brotherton Committee for the award of a Brotherton Research Scholarship and to the West Riding Education Authority for the award of a County Technological Scholarship.

\section{References}

Abrahams, S. C., Robertson, J. M. \& White, J. G. (1949). Acta Cryst. 2, 238.

Ahmed, F. R. \& Crutckshank, D. W. J. (1953). Acta Cryst. 6, 385.

Bamey, M. (1949). Acta Cryst. 2, 120.

Cox, E. G., DodgmL, M. W. \& Jefrrey, G. A. (1952). J. Chem. Soc. p. 4854.

Crutckshank, D. W. J. (1949). Acta Cryst. 2, 65.

EdCKen, A. \& Meyer, L. (1929). Phys. Z. 30, 397.

HARKER, D. \& Kasper, J. S. (1948). Acta Cryst. 1, 70.

Hunter, L. (1946). Rep. of Progr. Chem. 43, 141.

Jefrrey, G. A. \& PARry, G. S. (1952). J. Chem. Soc. p. 4864.

JefFrey, G. A. \& PARRY, G.S. (1953). Unpublished work.

McKeown, P.J.A., Ubbelohde, A.R. \& Woodward, I. (1951). Acta Cryst. 4, 391.

Marsden, R. J. B. \& Sutton, L. E. (1936). J. Chem. Soc. p. 1383.

Mathieson, A. McL., Robertson, J.M. \& Sinclair, V. C. (1950). Acta Cryst. 3, 251.

O'Gorman, J. M., Shand, W. \& Schomaker, V. (1950). $J$. Amer. Chem. Soc. 72, 4222.

Saksena, B. D. (1940). Proc. Indian Acad. Sci. A, 12, 416.

SHULL, D. R. (1947). Industr. Engng. Chem. 39, 517.

WaLlWork, S. C. \& Harding, T. T. (1953). Nature, Lond. 171, 40.

WincheLt, A.N. (1943). Optical Properties of Organic Compounds, p. 29. Madison: University of Wisconsin Press.

Wood, J.F. (1926). Proc. Univ. Durham Phil. Soc. 7, 111.

ZAHN, C. T. (1932). Phys.Z. 33, 730. 